\section{Georgia Homeowner Survey of Landscape Management Practices}

\author{
S. Varlamoff, ${ }^{1}$ W.J. Florkowski, ${ }^{2}$ J.L. Jordan, ${ }^{3}$ \\ J. Latimer, ${ }^{4}$ and K. Braman ${ }^{5}$
}

AdDITIONAL INDEX WORDS. gardening practices, fertilizer application, pesticide use, herbicide application, insecticide application, fungicide application

Summary. A survey of Georgia homeowners provided insights about their use of fertilizers and pesticides. Knowledge of current homeowner practices is needed to develop a best management practices manual to be used by Master Gardeners to train the general public through the existing outreach programs. The objective of the training program is to reduce nutrient runoff and garden chemicals and improve the quality of surface water in urban watersheds. Results showed three of four homeowners did their own landscaping and, therefore, fully controlled the amount of applied chemicals and the area of application. Fertilizers were primarily applied to lawns, but a high percentage of homeowners also applied them to trees, shrubs, and flowers. Insecticides were applied by a larger percentage of homeowners than herbicides. Control of fire ants (Solenopsis invicta) was likely the reason behind the frequent use of insecticides. The desire for a weed free lawn was the plausible motivation behind the use of herbicides, which were used mostly on lawns. Fungicide use was infrequently reported by Georgia homeowners. The pattern of fertilizer and pesticide use suggests that the developed manual should emphasize techniques and cultural practices, which could lower the dependence on chemicals, while ultimately assuring the desired appearance of turf and ornamental plants.

$M$ ore than $80 \%$ of American households participate in gardening activities (Behe and Beckett, 1993). According to the National Gardening Survey, the average household expenditures on gardening reached $\$ 452$ in 1998 (Butterfield, 1999). Between 1993 and 1998, residents of the southern U.S. increased lawn and gardening spending activities per household by $11 \%$ to $\$ 445$ (Butterfield, 1999). Georgia's mild climate and extended growing season from mid-April to

\footnotetext{
The cost of publishing this paper was defrayed in part by the payment of page charges. Under postal regulations, this paper therefore must be hereby marked advertisement solely to indicate this fact.

${ }^{1}$ Public relations coordinator, Center for Urban Agriculture, University of Georgia, Griffin, Campus, 1109 Experiment Street, Griffin, GA 30223-1797.

${ }^{2}$ Associate professor, Department of Agricultural and Applied Economics, University of Georgia, Griffin, Campus, 1109 Experiment Street, Griffin, GA 30223-1797.

${ }^{3}$ Professor, Department of Agricultural and Applied Economics, University of Georgia, Griffin, Campus, 1109 Experiment Street, Griffin, GA 30223-1797.

${ }^{4}$ Professor Department of Horticulture, Virginia Polytechnic Institute and State University, 301B Sauders Hall, Blacksburg, VA 24061

${ }^{5}$ Associate professor, Department of Entomology, University of Georgia, Griffin, Campus, 1109 Experiment Street, Griffin, GA 30223-1797.
}

mid-October encourages gardening. However, the cumulative impact of individual homeowners' fertilization, irrigation, pest management and other landscape practices can lead to environmental degradation of water, land, and biotic resources (Beverly et al., 1997).

Homeowners have fewer financial and regulatory incentives than farmers or landscape professionals when using garden chemicals. In 1995, 50\% of all households treated their yards with pesticides, fertilizers, or both (Templeton et al., 1998). In 1989, the National Academy of Sciences stated that homeowners tend to use as much as ten times more chemicals per acre on their lawns than farmers use on agricultural land (Jenkins, 1994). Larger doses are attributed to the popular belief that more is better. In Georgia, the U.S. Geological Survey reported the median concentration from urban watersheds of four major insecticides (chlorpyrifos, diazinon, carbaryl, and malathion) exceeded the U.S. Environmental Protection Agency guidelines for protection of aquatic life. Moreover, the concentrations of insecticides in urban watersheds were much higher than in agricultural watersheds (Frick et al., 1998).

Environmental and public health concerns have led to public demand for critical reassessment of current application methods of fertilizer and pesticides in urban surroundings (U.S. Environmental Protection Agency, 1993). The purpose of the current survey was to learn how homeowners maintain their landscapes with respect to fertilizer and pesticide use, what are their expectations regarding the appearance of their lawns, and what are their current gardening practices. Knowledge of the detrimental effects of garden chemical runoff on water quality in Georgia watersheds combined with the observation of homeowner practices is needed to develop educational materials promoting proper use of chemicals. A best management practices manual will be the primary tool developed from the survey results. The manual will contain information about the desired use of chemical inputs.

\section{Materials and methods}

This study required the development of a survey instrument for the purpose of gathering primary data because no readily available and current data exist on Georgia homeowner application of garden chemicals. A team consisting of agricultural economists, entomologists, horticulturists and environmental specialists developed a questionnaire concerning attitudes towards landscape maintenance. The drafted questionnaire was revised in cooperation with the University of Georgia Survey Research Center (SRC) (Athens, Ga.) staff recommendations.

A statewide survey of adult Georgians was conducted by the SRC during May and June 1999. The study called for conducting a total of 400 telephone interviews from a random digit dialed (RDD) sample of residents 18 years and older. The procedures ensured that all adults had an equal chance of being selected for inclusion in the sample. The 400 interviews represented a statistically significant random sample of Georgia homeowners. Bias in response was minimized and inferences about the general population were made from the obtained results at the $95 \%$ confidence interval (all answers $\pm 5 \%$ ).

The quality of the sample was determined by response rate, i.e., the proportion of members of the original sample who fully completed an interview. The cooperation rate for 
the study was $61 \%$ based on 1095 contacted households and 671 respondents who completed interviews. Because some respondents did not own a house, 271 granted interviews were excluded from the survey.

Attributes of respondents. The profile of the survey respondents differed significantly from the overall profile of the state's residents. The primary reason for the differences was the requirement of home ownership as a condition for survey participation. The basic assumption of the study was that gardening would most likely be a homeowner interest and that homeowners represent the group requiring education about the environmental effects of their practices.

Sixty-one percent of homeowners answering the Georgia survey were females as compared to the $51 \%$ female population living in the state (Boatright and Bachtel, 1998). The average age of those polled was 47 years, substantially higher than the average Georgian aged 33 years old in 1998. Seventy-six percent of respondents were married, considerably higher than the $55 \%$ of citizens married in the general state population. In addition, educational attainment level and the gross annual household income level were higher among homeowners than among the Georgia population at large. Twenty-three percent of Georgians were college graduates or received post graduate training, while $41 \%$ of those polled indicated a similar level of educational attainment. The average annual gross household income was $\$ 33,801$ in Georgia in 1998. In contrast, $44 \%$ of surveyed homeowners reported a gross annual household income exceeding $\$ 50,000$. Only $17 \%$ of the survey respondents indicated they lived in rural areas; whereas, $37 \%$ of all Georgians resided in rural areas in 1998. Differences be- tween general respondent characteristics and the average Georgian is consistent with the requirement of home ownership to participate in the survey.

\section{Results and discussion}

To understand how gardening chemicals are used, we classified practices as either general or specific. General gardening practices (Table 1 ) defined the principle areas where a homeowner might use fertilizers and insecticides. Questions pertaining to areas of application were posed to all survey respondents. Specific gardening practices (Tables $\mathrm{l}$ and 2) refer to plants to which homeowners applied fertilizer and pesticides. The set of questions on specific gardening practices was posed to those who performed their own landscape maintenance.

General gardening practices. The National Gardening Association Survey (Butterfield, 1999) determined that $84 \%$ of U.S. residents maintained their yards. According to the Georgia survey, a lower percentage of homeowners, $76 \%$, did their own landscape maintenance. Many residents in urban areas hire landscape maintenance professionals. According to the U.S. Environmental Protection Agency, Georgia had the highest number of certified professional chemical applicators $(76,518$ persons) across all states in 1997 (Aspelin and Grube, 1999).

Households give priority to nuisance pest control because they care about their own safety and because some of the pests impair recreation (Lajeunesse et al., 1997). Fire ants infest all of Alabama, Florida, Georgia, and Louisiana and parts of several other southern states (Sparks, 2000). Seventy-six percent of polled homeowners treated their

Table 1. General gardening practices, fertilizer use, and insecticide application in 1999 reported by homeowners in Georgia and elsewhere in the U.S.

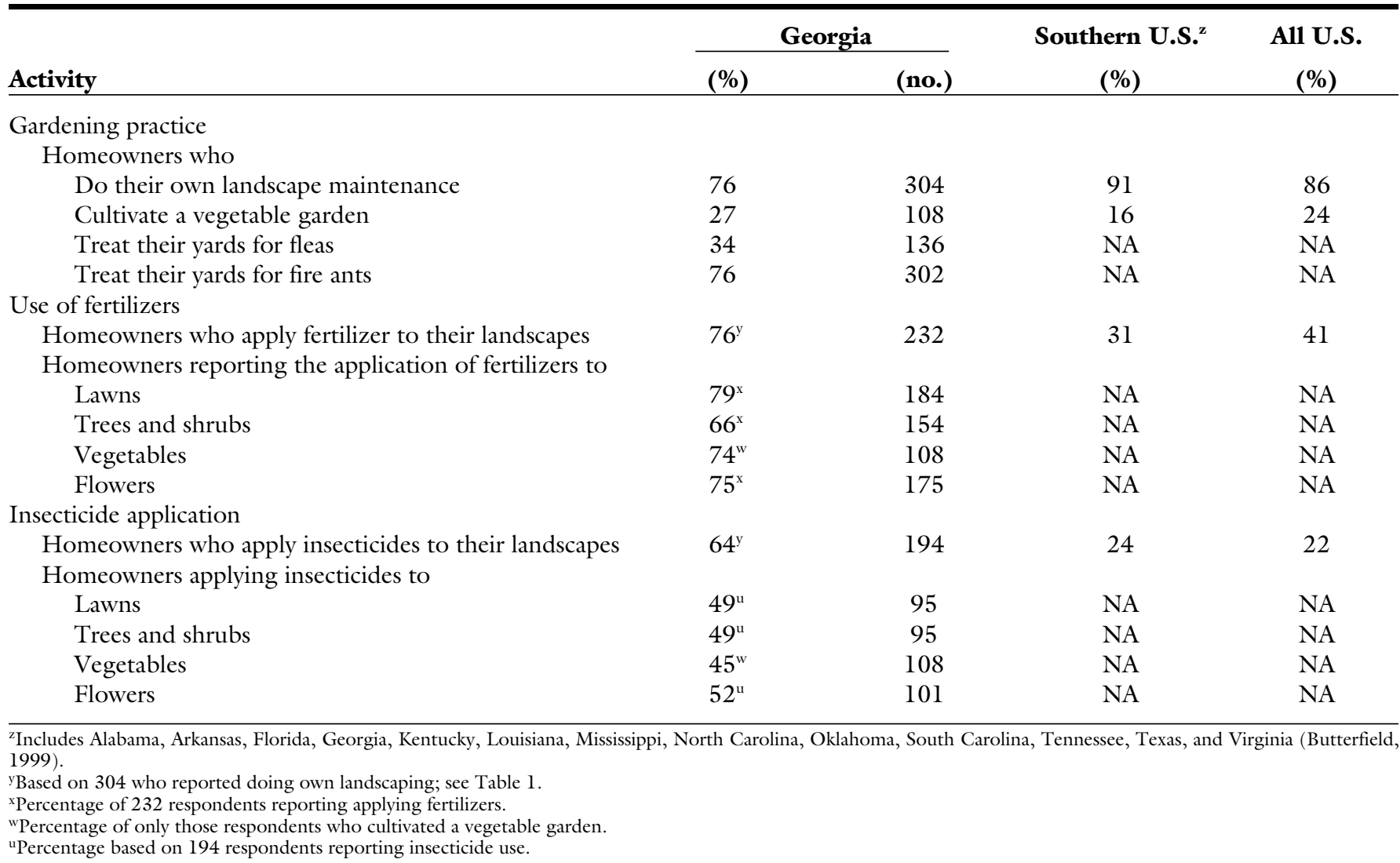


yards for fire ants (Table 1 ). Techniques to control fire ants include surface applications using paints, sprays, dusts, aerosols, granules or baits (Sparks, 1993). Applied products contain either carbaryl, chlorpyrifos, or diazinon which have been found in amounts exceeding safety levels for protection of aquatic life in urban watersheds (Frick et al., 1998). The percentage of Georgia homeowners who treat their yards for fire ants $(76 \%)$ was identical to those who reported doing their own landscape maintenance.

According to the National Gardening Association Survey, $24 \%$ nationally and $16 \%$ in the deep south of the U.S. (Alabama, Georgia, Louisiana, Mississippi, and South Carolina) grow vegetables. Georgians who cultivate vegetable gardens comprised $27 \%$ of homeowners. According to the Georgia gardening survey, interest in raising vegetables among homeowners exceeds that in the region and the nation. Despite challenging soil and climatic conditions, a long growing season may encourage this type of gardening. How vegetable gardening may influence the use of chemical inputs is important in determining the potential environmental effects and selecting areas for training needs.

Fertilizer USE. From the 1880s through the 1920s, U.S. culture shifted from a producer society to a consumer society. This transformation was evidenced in the residential landscape which consisted mostly of lawns and ornamentals (Jenkins, 1994). Popular magazines during that period offered advice on how to achieve the perfect front lawn that would announce the homeowner was a good neighbor and citizen. To keep grass green homeowners needed to supply it with fertilizer. In 1984, nearly one million tons of fertilizer were being applied to lawns in the United States (Jenkins, 1994).

Fertilizer is any of a large number of natural or synthetic materials, including manure, and containing nitrogen, phosphorus, and potassium compounds, spread on or worked into the soil to increase fertility. Nitrogen and phosphorus are essential nutrients for plant life, but when present at high concentrations in water, they may cause eutrophication of rivers and lakes. High concentrations of ammonia are toxic to aquatic life, while high concentrations of nitrates are toxic to humans and other animals (Frick et al., 1998). Phosphorus runoff in the Minneapolis-St. Paul, Minn. metropolitan area was attributed to phosphorus fertilizer applications, especially to lawns with already high levels of fertility (Barten and Jahnke, 1997). In particular, well maintained lawns may have reduced soil erosion, but increased phosphorus runoff.

In the southern U.S., soils are highly weathered and organic matter levels are low requiring the addition of nutrients (Plank, 1996). For balanced turfgrass growth, fertilizer is usually applied in three to five applications during the growing season (Landry, 1996). Seventy-six percent of Georgia homeowners applied fertilizers to their landscape (Table 1 ), a number identical to those who reported doing their own landscape maintenance.

Among the surveyed Georgia homeowners, 54\% expressed the desire to have their lawn of comparable quality to their neighbors. This result is consistent with a study of residents of Dakota County, Minn., which reported that $66 \%$ considered it "very important" or "somewhat important" to have their lawn look as good as their neighbors (Morris and Traxler, 1996). Furthermore, $56 \%$ of polled Georgia homeowners considered it "somewhat important" to "very important" to have a green lawn throughout the year. To maintain a green lawn year-round requires the use of grass varieties which demand fertilizer applications during several seasons (Landry, 1996). Earlier surveys showed that many homeowners “don't know" how much fertilizer to use on turfgrasses (Carpenter and Meyer, 1999). Fewer than $6 \%$ of respondents in Edina, Minn., knew how much fertilizer was needed yearly for a medium maintenance lawn. In Georgia, many residents tend to overfertilize centipede grass (Eremochloa ophiuroides) (Landry, 1996). Seventynine percent of Georgia homeowners who reported using fertilizers on their landscape, applied them to their lawns (Table 1). Similarly, a Dakota County Minn. study indicated $75 \%$ of those polled reported fertilizing their yards (Morris and Traxler, 1996).

About two-thirds of homeowners (66\%) confirmed that they fertilized shrubs and trees. The share of those who fertilized these type of plants is only slightly smaller than those fertilizing lawns. Georgia Cooperative Extension Service recommendations exclude application of fertilizers to mature trees and shrubs "as long as they exhibit good leaf color and reasonable growth" (Midcap, 1996). However, the fast growth of residential housing units and the installation of lawns and young landscape plants may justify, in part, this level of fertilizer use by Georgia homeowners. Georgia's population grew at a fast pace during the last two decades and the state's home ownership rate surpassed the national average (U.S. Dept. of Commerce, 2000).

In Georgia, successful fruit, vegetable and flower gardening requires fertilization to grow quality produce and attractive flowers (Ferree and Krewer, 1996). Results of this survey support, however, the limited importance of vegetable gardening for homeowners. Though only $27 \%$ of respondents confirmed having vegetable gardens, $74 \%$ of those who were engaged in the production of vegetables applied fertilizer. A nearly equal percentage (75\%) of Georgia homeowners fertilized their flowers (Table 1).

Pesticide use. The expected benefits of outdoor pesticide use by homeowners include comfort and safety from pests and enhanced appearance of yards (Templeton et al., 1998). The average household spent about $\$ 20$ on pesticides (Aspelin and Grube, 1999). However, since 1979, pesticide use by the home and garden sector has decreased by $12 \%$. Despite pesticide use decline, herbicide use has increased by $48 \%$ since 1979 . Herbicides accounted for $64 \%$ of all pesticides applied in 1995 (Baldson, 1996).

Herbicide application. Herbicides are used frequently to kill weeds in turfgrass to improve its appearance. Nonselective herbicides kill plants regardless of species and are applied at 10 times the rate of similar compounds used for selective weed control (Frick et al., 1998). Higher application rates increase the likelihood that herbicides can be present in nearby streams (Frick et al., 1998). Selective herbicides control certain plant species without seriously affecting the growth of another plant species. According to the survey results (Table 2), $42 \%$ of homeowners applied herbicides to their landscapes. On a per acre basis, treated urban landscapes received eight times the amount of active ingredients of 2,4-D (2,4-dichlorophen oxyacetic acid) and other phenoxy herbicides than treated rural landscapes (Templeton et al., 1998). In households where 2,4-D was applied to lawns, it has been determined that there is increased probability of pet cancer (Hayes et al., 1995). 2,4$\mathrm{D}$, a chlorinated phenoxy compound, is a selective herbicide 


\begin{tabular}{|c|c|c|}
\hline Activity & \multicolumn{2}{|c|}{ Response } \\
\hline \multicolumn{3}{|l|}{ Herbicide application } \\
\hline \multicolumn{3}{|c|}{ Homeowners reported using herbicides } \\
\hline On lawns & $68^{y}$ & 86 \\
\hline Near flowers & $34^{y}$ & 43 \\
\hline \multicolumn{3}{|l|}{ Fungicide application } \\
\hline Homeowners who apply fungicides & $23^{\mathrm{z}}$ & 70 \\
\hline \multicolumn{3}{|c|}{ Homeowners reported using fungicides } \\
\hline On lawns & $29^{w}$ & 20 \\
\hline Near trees and shrubs & $50^{\mathrm{w}}$ & 35 \\
\hline
\end{tabular}

${ }^{\mathrm{z}}$ Based on 304 who reported doing own landscaping.

y Percentage of 126 homeowners reporting herbicide use.

xercentage of 108 homeowners who cultivated a vegetable garden.

wPercentage based on 70 respondents reporting fungicide use.

found in high concentrations in urban watersheds in Georgia. Herbicides, in general, were detected in greatest concentrations of all landscape chemicals. Nonselective herbicides comprised the largest group of these herbicides present in urban watersheds (Frick et al., 1998).

According to the survey results, $76 \%$ of homeowners rated a weed-free lawn as either "very important," "important" or "somewhat important." An earlier Minnesota survey revealed that a typical homeowner tolerated up to $10 \%$ weeds in their lawns (Carpenter and Meyer, 1999). In support of a low tolerance for weeds and the perceived importance of a weed-free lawn, $68 \%$ of Georgia homeowners indicated they applied herbicides to their lawns (Table 2 ). High application of herbicides increases the potential for runoff into nearby surface waters.

Benefits of using herbicides include increased growth rate and vigor of woody plants by eliminating weeds from the plant base (Murphy, 1996), but once a tree or shrub is established, it no longer requires herbicide application (Midcap, 1996). Surveyed Georgia homeowners indicated only $31 \%$ of those using herbicides applied them near trees and shrubs (Table 2). Vegetables are also sensitive to herbicides applied near them. Herbicides may reduce early vigor and growth (Murphy, 1996). Nineteen percent of those cultivating vegetables used herbicides near vegetables.

Flowers cannot thrive if weeds are present and exhibit the same susceptibility to herbicides as vegetables (Thomas, 1994). Only 34\% of Georgia survey respondents who applied herbicides in their landscapes indicated using herbicides to control weeds near flowers. Extreme caution is required when using a herbicide near flowers because very few herbicides are suitable for application in flower gardens (Thomas, 1994).

INSECTICIDE APPLICATION. Nationally, consumers spent an average of \$77 per household on insect control in 1998 (Butterfield, 1999). Maintaining the aesthetics of a southern U.S. landscape requires controlling insect populations. Insecticides can improve the quality of edible produce or flowers. However, in recent years, U.S. consumers have often expressed concerns about the use of chemical insecticides leading to government involvement in promotion of urban integrated pest management (Daar, 1997). The program contributed to the $12 \%$ reduction in insecticide usage since 1979 (Aspelin and Grube, 1999).

Despite concerns about potential health and safety problems related to insecticide use, homeowners seldom are concerned with broader implications of their outdoor insect control. For example, many homeowners are unaware that most insects are beneficial to the landscape and only $3 \%$ are considered pests (Sparks, 1996). Some homeowners treat symptoms of pest problems without adequate information about the causes, and often are unfamiliar with nonchemical pest management (Templeton et al., 1998).

The National Gardening Association Survey reported that $24 \%$ of residents of the southern U.S. controlled insects in 1998 (Butterfield, 1999). Georgia's climate is particularly hot and humid from May through September providing favorable breeding conditions for many insects. These conditions may contribute to the high use of insecticides. In contrast to the national survey, $64 \%$ of Georgia homeowners who do their own landscaping applied insecticides (Table 2 ). Typical broad range insecticides (carbaryl, chlorpyrifos, diazinon, and malathion) are the same compounds that appear in high concentrations in urban watersheds in Georgia. Carbaryl, diazinon, and malathion have been suspected human carcinogens (Day et al., 1995). Common lawn insect pests include those living in soil, e.g., white grubs (Phyllóphaga sp.) that feed on roots of grasses and other plants, and above ground, e.g., spittlebugs (Philaenus sp.) or chinch bugs (Blissus leucópterus) (Sparks and Hudson, 1993). Damage to lawns can result from pests and/or fungal disease. Before choosing the appropriate control method, proper identification of pest and/or disease is important.

Trees and shrubs are attacked by myriad insects including aphids from the genera Dysàphis, Rhopalosiphum, Àphis, Macrosiphum, Acyrhosiphon and Brevicòryne, and whiteflies from the genus Aleurocanthus, and scale insects from the 
genera Planocóccus and Pseudocóccus (Sparks and Hudson, 1994). Homeowners are rarely trained to identify these pests and are typically unaware of a problem until there is an infestation. Insect control through application of insecticides can be difficult on mature plants. In the case of young plants, the cooperative extension service recommends installing pest resistant plants. Some people tend to over apply because the minor income loss of wasted pesticides is less important as their income increases (Templeton et al., 1998). About 49\% of Georgia homeowners who applied insecticides, applied them also on their lawns and trees and shrubs (Table 2). Fewer (45\%) applied insecticides on vegetables. More than half $(52 \%)$ of Georgians who reported doing their own landscaping applied insecticides to their flowers.

Fungicide application. About 8,000 species of parasitic fungi can cause plant diseases in Georgia (Baldson, 1996). Among pesticides, fungicides account for only 5\% (by volume) of pesticides used by homeowners nationwide (Aspelin and Grube, 1999) and their use has decreased by 53\% since 1979 (Aspelin and Grube, 1999). Twenty-three percent of state homeowners applied fungicides (Table 2). Fungicides are least toxic pesticide and their infrequent use is probably due to the general public's inability to identify fungal diseases and choose the appropriate fungicide treatment (R. Westerfield, personal communication). Often insecticides are applied on misdiagnosed fungal infections. Fungicide applications do not generate an immediately observable effect on the plant. Furthermore, fungicide applications can be costly because most are not systemic and have a short residual time and must be frequently reapplied.

In the case of lawn care, fungicides require large volumes of liquid because spraying is the common application method. Only $29 \%$ of polled homeowners, who used fungicides, applied them to their lawns (Table 2). Fifty percent applied fungicides to trees, shrubs, and flowers, while $42 \%$ applied to vegetables. Fungicides do not represent a threat to surface water quality in Georgia urban watersheds (Frick et al., 1998).

\section{Conclusions}

Three of every four homeowners are engaged in landscape maintenance in Georgia. Among them, nearly four of five reported applying fertilizers to lawns. Only a slightly lower number applied fertilizer to trees and shrubs and flowers. Fertilizer runoff is frequently blamed for the nitrogen and phosphorus pollution of surface water and represents a danger to aquatic life. Significant precipitation in Georgia coincides with the spring fertilizer applications, resulting in the potential for high runoff.

Homeowners need to learn that fertilizer applications on lawns will be less costly if their timing and application rate match the needs of the grass variety used in the landscape. The ability to recognize the grass type and distinguish between cool season and warm season grasses is particularly important in Georgia where both grass types are commonly used. More important is the need to educate homeowners about the real fertilizer needs of mature trees and shrubs.

Some herbicides used in turfgrass maintenance have been found in urban watersheds in Georgia. Forty percent of homeowners, who did their own landscaping applied herbicides, with a majority applying herbicides on lawns. Confirmed findings of nonselective herbicides commonly available to homeowners in water samples in urban areas represent indirect evidence linking the pollution and herbicide usage by homeowners. A weed free lawn is an ambition of many participating homeowners who may lack knowledge of cultural practices and their influence on weed presence in lawns. Mowing height, watering, fertilizer application and turf variety all contribute to the presence or absence of weeds depending on their application. These simple practices may be poorly understood and inconsistently implemented by homeowners. Whereas the use of these techniques saves the cost of purchasing herbicides, they still demand additional effort on the part of a homeowner. The convenience of herbicide use will remain a major obstacle in changing landscape maintenance habits.

The general use of insecticides was found to exceed that of herbicide use among Georgia homeowners. The primary reason behind a high insecticide use are likely fire ant colonies now present in almost all Georgia counties. However, some insecticides used to control fire ants act selectively and pose little danger to other insects. Educational efforts may have to concentrate on the use of insecticides in flowers, while training homeowners to determine a true threshold level of infestations in case of lawns, trees, or shrubs. The presence of harmful insects does may not necessitate immediate homeowner intervention. Many plants including grasses can withstand damage inflicted by insects without succumbing to sickness or death. Ability to identify harmful insects as well as their primary predators may discourage the use of insecticides. A well balanced ecosystem can often keep pest numbers to a nondestructive level through biological control. In addition, there are less toxic or more benign methods of pest control such as horticultural oils and soaps that are effective when applied during certain stages of an insect's life cycle these are toxic to the pest.

It is important to educate homeowners on the detrimental effects of insecticides on beneficial insects such as those that pollinate flowers and those that add beauty to the landscape, such as butterflies (Lepidoptera). A separate group that needs continuing education are homeowners raising fruits and vegetables. Insect and disease resistant vegetable varieties may alleviate the danger of environmental damage stemming from insecticide use, but changes in cultural practices can also be encouraged to reduce the prevalence of pests.

The proposed best management practices manual, intended for training gardeners in Georgia, must address the currently observed behavior regarding the use of garden chemicals. Homeowners were found to be receptive to the dissemination of practices reducing the threat of environmental pollution, lowering the maintenance cost and reducing their workload, while conforming to neighborhood norms. As a reference source, the manual must recognize conflicting preferences of homeowners for convenience, improved appearance of landscapes, and the desire to limit negative environmental damage. Furthermore, information about the use of pesticides should indicate potential risks to applicators and guidelines for proper storage, preparation, and disposal of excess sprays and empty containers. 


\section{Literature cited}

Aspelin, A.L. and A.H. Grube. 1999. Pesticides industry sales and usage, 1996 and 1997 market estimates. 733-R-99-001. Office of Prevention, Pesticides, and Toxic Substances, U.S. EPA, Wash., D.C.

Baldson, J.A. 1996. Basic plant pathology, p. 51-62. In: M.E. Ferree (ed.). The Georgia Master Gardener handbook. Univ. of Georgia, Athens, Coop. Ext. Serv., College of Agr. Environ. Sci.

Barten, J.M. and E. Jahnke. 1997. Suburban lawn runoff water quality in the twin cities metropolitan area, 1996 and 1997. Suburban Hennepin Region Park District Rpt., Maple Plain, Minn.

Behe, B. and L. Beckett. 1993. Horticultural industry development 1970-1993. Proc. S. Nurserymens Assn. Res. Conf. 38:398400 .

Beverly, R.B., W. Florkowski, and J.M. Ruter. 1997. Fertilizer management by landscape maintenance and lawn care firms in Atlanta. HortTechnology 7:442-445.

Boatright, S.R. and D.C. Bachtel, 1998. Passport to Georgia-A statistical journey. Dept. of Housing and Consumer Sci., College of Family and Consumer Sci., Univ. of Georgia, Athens.

Butterfield, B.W. 1999. National gardening survey 1998-1999. Natl. Gardening Assn., Burlington, Vt.

Carpenter, P.J. and M.H. Meyer. 1999. Edina goes green Part III: A survey of consumer lawn care knowledge and practices. HortTechnology 9:491-494.

Daar, S. 1997. Structural IPM successes at NASA's Ames Research Center. The IPM Practitioner 19:1-11.

Day, K.A., B.A. Kuhn, and A.M. Vandeman. 1995. Measuring the food safety risk of pesticides, p. 393-410. In: J.A. Caswell (ed.). Valuing food safety and nutrition. Westview Press, Boulder, Colo.

Ferree, M.E. and G. Krewer. 1996. Fruit gardening, p. 240-310. In: M.E. Ferree (ed.). The Georgia Master Gardener handbook. Univ. of Georgia, Athens, Coop. Ext. Serv., College of Agr. Environ. Sci.

Frick, E.A., D.J. Hippe, G.R. Buell, C.A. Couch, E.H. Hopkins, D.J. Wangsness, and J.W. Garrett. 1998. Water quality in the Apalachicola-Chattahoochee-Flint River Basin, Georgia, Alabama, and Florida, 1992-95, U.S. Geological Survey Circ. 1164. U.S. Geol. Survey, Denver, Colo.

Hayes, H.M., R.E. Tarone, and K.P. Cantor. 1995. On the association between canine malignant lymphoma and opportunity for exposure to 2-4-dichlorophenoxyacetic acid. Environ. Res. 70:119-125.
Jenkins, V.S. 1994. The lawn-A history of an American obsession, Smithsonian Inst. Press, Wash., D.C.

Landry, Jr., G. 1996. Lawns in Georgia. Univ. of Georgia, Athens, Coop. Ext. Serv., College of Agr. Environ. Sci. Bul. 773.

Lajeunesse, S.E., G.D. Johnson, and J.S. Jacobson. 1997. A homeowner survey-Outdoor pest management practices, water quality awareness, and preferred learning methods. J. Natl. Resource Life Sci. Edu. 26:43-48.

Midcap, J.T. 1996. Urban trees, p. 348-383. In: M.E. Ferree (ed.). The Georgia Master Gardener handbook. Univ. of Georgia, Athens, Coop. Ext. Serv., College of Agr. Environ. Sci.

Morris, B. and D. Traxler. 1996. Dakota county subwatershed residential survey on lawn care and water quality. Dakota County Environ. Educ. Program, Eagen, Minn.

Murphy, T.R. 1996. Weed science, p. 73-83. In: M.E. Ferree (ed.). The Georgia Master Gardener handbook. Univ. of Georgia, Athens, Coop. Ext. Serv., College of Agr. Environ. Sci.

Plank, C.O. 1996. Soils and plant nutrition, p. 15-33. In: M.E. Ferree (ed.). The Georgia Master Gardener handbook. Univ. of Georgia, Athens, Coop. Ext. Serv., College of Agr. Environ. Sci.

Sparks, B. 1993. Controlling fire ants in urban areas. Univ. of Georgia, Athens, Coop. Ext. Serv., College of Agr. Environ. Sci. Bul. 1068.

Sparks, B. and W. Hudson. 1993. Insect pest of home lawns. Univ. of Georgia, Athens, Coop. Ext. Serv., College of Agr. Environ. Sci. Bul. 1094

Sparks, B. and W. Hudson. 1994. Control of common pests of landscape plants. Univ. of Georgia, Athens, Coop. Ext. Serv., College of Agr. Environ. Sci. Bul. 1074.

Sparks, B. 1996. Basic entomology, p. 35-50. In: M.E. Ferree (ed.). The Georgia Master Gardener handbook. Univ. of Georgia, Athens, Coop. Ext. Serv., College of Agr. Environ. Sci.

Sparks, B. 2000. Management of red imported fire ants, p. 1-5. In: S. Varlamoff (ed.). Landscape management manual. Univ. of Georgia, Athens, College of Agr. Environ. Sci.

U.S. Dept. of Commerce. 2000. Statistical abstract of the United States 1999. Wash., D.C.

Templeton, S.R., D. Zilberman, and S.J. Yoo. 1998. An economic perspective on outdoor residential pesticide use. Environ. Sci. \& Technol. News 10(1):416-423.

Thomas, P.A. 1994. Flowering perennials for Georgia flowers, 1994. Univ. of Georgia, Athens, College of Agr. Env. Sci. Bul. 944.

U.S. Environmental Protection Agency. 1993. Lawn care pesticides. White Paper. U.S. EPA, Wash., D.C. 